\title{
Production Specialization and Trade Blocs
}

\author{
Deng-Shing Huang \\ The Institute of Economics, Academia Sinica \\ Yo-Yi Huang \\ National Taiwan Ocean University \\ Ying-Chih Sun \\ National Taiwan Ocean University
}

\begin{abstract}
Using the clustering analysis and gravity model, this paper investigates the evolution of likely trade-bloc phenomenon for the textile industry and the automatic data processing industry for the last three decades. For the textile industry, a significant two-bloc phenomenon could be identified, one declining bloc mainly composed of the European countries, and the other rising bloc of countries around Pacific Rim. For the automatic data processing industry, only one trade bloc could be identified. However, the core countries have gradually changed from those of Europe and USA to the countries of East Asia over the period.
\end{abstract}

- JEL classification: F14, F15

- Keywords: Two-bloc phenomenon, Textile industry, Automatic data processing industry, Gravity model, Globalization, Production disintegration

\footnotetext{
*Corresponding address: Deeng-Shing Huang, The lnstitute of Economics. Academia Sinica, No. 128 Sec. 2 Academia Rd., Nankang Taipei 115, Taiwan. E-mail: dhuang@econ.sinica.edu.tw, Tel: 886-227822791 ext 204, Fax: 886-2-27853946; Yo-Yi Huang, Institue of Applied Economics, National Taiwan Ocean University, No. 2, Pei-Ning Rd., Keelung 202, Taiwan. E-mail: hyy@ntou.edu.tw, Tel: 886-2-27822791 ext 5412; Ying-Chih Sun, Institute of Applied Economics, National Taiwan Ocean University, 2, Pei-Ning Rd., Keelung 202, Taiwan. E-mail: m92350014 @alumni.ntou.edu.tw. (C2006-Center for International Economics, Sejong Institution, All Rights Reserved.
} 


\section{Introduction}

During the last three decades, the world trade system has experienced a dramatic change, along with the collapse of communism communities, the opening of China and advanced economic and political integration of the Europe. Probably being stimulated by the phenomenon, academia studies on trading blocs and regionalism fostered in the literatures during the periods, e.g., Eichengreen and Irwin (1995, 1996), Krugman (1995), Feenstra et al (2001), and Frankel and Wei (1995) just to name a few. In general, the gravity model has been widely adopted in these studied. ${ }^{1}$ For example, Eichengreen and Irwin $(1995,1996)$ apply the model on the 1928 data to investigate the effect of trading blocs and currency blocs on the flows of trade. The phenomenon of trading blocs did not disappear despite the development of GATT after the World War II. On the contrary, the bloc phenomenon seems to foster even faster than before. ${ }^{2}$ Frankel (1992) uses this approach to investigate whether Japan has formed a Yen-bloc in the East Asian and Pacific Basin in the 1980s. Frankel and Wei (1995) use the gravity approach to examine the phenomenon of regionalism in Asia. Rauch (1999) uses the gravity model to inspect the effect of common language, colonial relationship, and the product differentiation on the networks of trade.

On the other hand, the production process becomes more and more internationally disintegrated, due to the availability of technology and globalization. In fact, globalization and production disintegration interacts with each other. The globalization phenomenon, in terms of trade in final and/or intermediate goods, the flows of capital as well as the migration of skilled and unskilled labors, has advanced the degree of cross-border production process. ${ }^{3}$ We could easily find that the production of a given commodity often involves many countries. In other words,

${ }^{1}$ The development of gravity model can be dated back to 1960s, initiated by Tinbergen, J. (1962) and Linnemann, H. (1966). Although the model was lack of a theoretical foundation in the earlier stage of development, Deardorff (1984)'s survey confirms the effective performance of the model in explaining the world trade flows. Consequently, the gravity model became a commonly adopted approach to conduct analysis on the regionalism and/or globalization issues. Theoretical foundation for the gravity equation was firstly established by Anderson (1979) and followed by Berstrand (1985), Feenstra et al (2001) etc.

${ }^{2}$ See Grant et al (1993) for the related discussion.

${ }^{3}$ In fact, the phenomenon that output markets, factor markets and the production process become more and more integrated on one hand, and more and more mutually dependent on the other hand, is itself a definition of globalization. See Nunnenkamp et al (1994) for the definition of globalization. 
the production activity for a single product is in general beyond the scope of country boundary, so-called the phenomenon of "disintegration of production". ${ }^{4}$ Of course, the vertically disintegrated production process often occurs in the foreign subsidiaries of a multinational firm, inducing an intra-firm trade. According to a survey on the US and Japanese firms, Bonturi and Fusakaku (1993) found that the intra-industry trade significantly increases due to the current of FDI in the 1980s; the FDI-induced intra-firm trade accounts for about 35 to $40 \%$ of the US trade.

However, the scope of vertical production network is not unlimited. Instead, it is limited to some related countries, depending on the geological relation for the consideration of transport costs, and/or the availability of technology normally spreading through the multinational firms' direct investment abroad. As is discussed by Vernables (1996), the transport cost in the trade of intermediate product affects not only the composition of countries in the production process of a certain industry, but also the geographical composition of trade in final products. In other words, the degree of production disintegration and countries involved vary from industry to industry. However, existing literature on the trading bloc, especially those applying the gravity model to search empirical evidence, mostly confines their analysis on the total volume of trade (hereafter denoted as VOT), failing to take into the consideration of industry-specific features that seems to play a significant role in the formation of trading bloc. As a complementary study, this paper will focus on the phenomenon of trading blocs from industry-level point of view. Thus, we choose two technologically different industries, the textile industry and the automatic data processing equipment industry for our analysis.

The textile industry represents a conventional, mature and technologically lower and more standardized industry. In this regard, more countries are expected to be able to involve in the activities of producing and trading in the world market. The industry is basically composed of three SITC 2-digit commodities: SITC26 (Textile Fibers, including both the natural and synthetic fibers), SITC65 (Textile Yarn, Fabrics and related Products) and SITC84 (Articles of Apparel and Clothing Accessories). Basically, the three categories form the textile industry from upstream, middle stream to down stream. On the contrary, the automatic data processing equipment industry (classification of SITC 75) is a relatively modern and tech-intensive industry, a well-developed industry not until the recent decades. Thus, from the viewpoint of history and technology availability, we may intuitively

${ }^{4}$ For the interaction between the globalization and vertical specialization, refers to Feenstra (1998). 
expect a wide spread of international disintegration of production in the textile industry than in the automatic data processing industry. The concentration ratio in the volume of trade indeed reveals this guess to some extent. In 1970, for the textile industry the top 20 trade-volume countries account for $75.17 \%$ of the world volume of trade. The corresponding figure reduces to $64.74 \%$ in $1980,68.50 \%$ in 1990 and $64.05 \%$ in 2000 , as shown in the last row of Table 1 . For the automatic data processing industry, as shown in Table 3, the VOT share in the world of the top-20 trading countries accounts for $92.44 \%$ in $1970,89.18 \%$ in $1980,92.68 \%$ in 1990 , and $90.91 \%$ in 2000 , indicating a relatively limited distribution of countries involved in the modern industry.

The rest of this paper is organized as follows: Section II provides the empirical methods, introducing two complementary approaches to be adopted to identify a trading bloc, that is, the hierarchical cluster analysis and the gravity model. As will be clear later, in the first step, a hierarchical cluster analysis on the bilateral trade intensities of each industry is designed to identify bloc of countries, in which a relatively higher intra-bloc trade occurs. Then, in the gravity model, those trading blocs identified in the first step are designed accordingly as bloc variables, on which we then test whether the intra-bloc trade intensity is empirically greater than normal level implied by the corresponding market factors (represented by the gravity variables of GNP per capita, GDP and geographical distance, etc) and investigate the evolution of trading blocs during the past three decades. For example, if a group of countries is identified as a trade cluster in a given industry, said group A in textile trade in 1970, then will the cluster become more integrated or less integrated in the last three decades? On the other hand, there might exist identified cluster in the 2000 that is not identified in the early years of 1970 and 1980 etc. On the contrary, a cluster that has been confirmed in the 1970 may expand or shrink in terms of member countries in the later years of $1990 \mathrm{and} /$ or 2000. Section III provides empirical results for both the textile industry, section IV for the industry of automatic data processing equipments. Section V concludes the paper.

\section{Empirical Method}

Theoretically, a trading bloc can be defined as a group of countries characterized by relatively higher intra-group trade than 'normal' level. Thus, two empirical methods are sequentially conducted in the study. They are firstly, the hierarchical 
cluster analysis, and then the gravity model to investigate rigorously whether a trading bloc identified by the cluster analysis exists. Furthermore, if a trading bloc does exit significantly in certain years, then we would like to use the gravity model to examine how the trade intensity within the group has changed over time. For a bloc of disintegrating over time, the intra-group trade intensity would be expected to be declining. On the contrary, a bloc of getting more integrated, we would expect higher and higher trade intensity within the group.

\section{A. Cluster Analysis on Bilateral Trade Intensities}

The hierarchical cluster analysis based on bilateral trade intensity is adopted for the textile industry and automatic data processing industry, to identify bloc of countries with strong trade linkage. More specifically, the first step is to compute the bilateral trade intensity (denoted as $T_{i j}$ ), which is defined as the ratio of trade volume between the countries of $i$ and $j$ to the total volume of world trade. That is, $T_{i j} \equiv\left(X_{i j}+X_{i j}\right)^{\prime} \sum_{i} \sum_{j} X_{i j}$ where $X_{i j}$ denotes the value of export from country $\mathrm{i}$ to $\mathrm{j}$ for a given commodity. The inverse of $T_{i j}$, i.e. $1 / T_{i j}$, is then to represent the 'distance' between countries $i$ and $j$. The economic intuition for this setup is clear. That is, the higher the trade intensity between countries, the smaller the 'economic distance' in between, and the more reasonable be regarded as being belong to the same cluster.

The second step is to link the countries into "hierarchical clusters" according to the density-linkage algorism. See Duran and Odell (1974), Artist and Zhang (2001) for more details of the approach. That is, in the beginning when each country represents its own cluster, the distance is simply the distance represented by the inverse of bilateral trade intensity defined as above. For clusters containing more than one element, the distance is defined as the average distance of the closest element in each cluster. All the countries will finally be linked together to form trading blocs, and the resulting blocs tend to represent long "chains", as can be illustrated by a tree diagram.

The bilateral trade data are from the World Trade Database of Statistics, Canada, which is based on the UN's COMTRADE data. Four years of 1970, 1980, 1990 and 2000 are selected for analysis. For every year, the top 20 countries in VOT share in the world trade are included for clustering, to be listed in Table 1 for textile industry, and Table 3 for the automatic data-processing industry. The results are described by tree diagram of Figure 1 and 2 for the textile and automatic data processing industries respectively, and discussions will be made in section 3 and 4 . 
Each of the identified trading blocs is then based on to establish a regional dummy in the gravity equation, and will be tested econometrically to examine whether the bloc's intra-group trade intensity is increasing or decreasing over the last three decades. It will be helpful to introduce the gravity model before we proceed further.

\section{B. Gravity Equation Estimation}

Starting from Tinbergen (1962) and Linneman (1966), the gravity model has been shown to be empirically successful in explaining bilateral trade flows. ${ }^{5}$ The theoretical foundation of the gravity model can be found in Anderson (1979), Bergstrand (1985), and Feenstra et al (2001). The traditional gravity equation usually takes the following log-linear form: ${ }^{6}$

$$
\begin{aligned}
\log \left(V O T_{i j}\right)= & \alpha+\beta_{1} \log \left(G D P_{i} \cdot G D P_{j}\right)+\beta_{2} \log \left(G N P P C_{i} \cdot G N P P C_{j}\right) \\
& +\beta_{2} \log \left(D I S T_{i j}\right)+\sum_{k} \delta_{k} C N T G_{i j}^{k}+\sum_{r} \eta_{r} R G N_{i j}^{r}+u_{i j}
\end{aligned}
$$

where $V O T_{i j}$ denotes the volume of trade between country $i$ and $j$ (i.e., $\left.V O T_{i j}=X_{i j}+X_{j i}\right) ; G D P_{i}$ is the gross national product of country $i$; GNPPC $C_{i}$ is the GNP per capita of $i$; and $D I S T_{i j}$ is the transport distance between $i$ and $j$. In addition, $C N T G_{i j}^{k}$ is a contiguity dummy, which is defined as follows: If both country $i$ and $j$ are of the $k$ cluster (for example, common language, border, or cultural background), then $C N T G_{i j}^{k}=1$, otherwise $C N T G_{i j}^{k}=0$. The term $R G N_{i j}^{r}$ is a region dummy, which is defined as $R G N_{i j}^{r}=1$, if both $i$ and $j$ belong to the same particular region of $r$, e.g., members of the same regional trade arrangement, free trade area, common market etc; otherwise, $R G N_{i j}^{r}=0$. In this study, we form the region dummy according to the trading bloc identified by the cluster analysis. Obviously, $u_{i j}$ denotes an error term.

Except for the region dummy, the other three groups of factors determine the basic gravity model. That is, bilateral trade flows between countries are in principle determined by the following three kinds of factors: (1) gross domestic products and GNP per capita, (2) transport distance, and (3) contiguity factors. Among the three, the first category denotes economic variables. They reflect the trade needs arising from economic incentives, as discussed in the conventional trade theory. Normally,

${ }^{5}$ See Deardorff (1984) for a survey.

${ }^{6}$ See Frankel (1992), Feenstra et al. (2001), and references therein. 
a greater $G D P$ and national income would induce a larger demand for foreign goods and thus lead to more trade flows between the countries. That is, theoretically we would expect a positive relationship between volume of trade and the two variables of $\log \left(G D P_{i} \cdot G D P_{j}\right)$ and $\log \left(G N P P C_{i}\right.$. $\left.G N P P C_{j}\right)$, i.e., $\beta_{1}>0$, $\beta_{2}>0$. Intuitively, a positive coefficient of $\log \left(G D P_{i}\right.$. $\left.G D P_{j}\right)$, to be rewritten as $L G D P_{i j}$ hereafter, ${ }^{7}$ also indicates a positive relationship between market size and volume of trade. In the extreme case, either $G D P_{i}$ or $G D P_{j}$ approaching zero will result in no trade in between. A positive coefficient of the variable $\log \left(G N P P C_{i}\right.$. $G N P P C_{j}$ ), rewritten as $L G N P P C_{i j}$, also reflects a positive marginal import propensity as indicated by the trade theory. It also represents the income similarity argument in the new-trade theory of the 1980s. That is, the higher the degree is of income similarity between countries, the greater the intra-industry trade will be. ${ }^{8}$

For our purpose, we skip the contiguity dummy $C N T G_{i j}^{k}$, and retain in the gravity equation the region dummies $R G N_{i j}^{r}$ to be designed according to the trading blocs identified in cluster analysis, that is,

$$
\begin{aligned}
\log \left(V O T_{i j}\right)= & \alpha+\beta_{1} \log \left(G D P_{i} \cdot G D P_{j}\right)+\beta_{2} \log \left(G N P P C_{i} \cdot G N P P C_{j}\right) \\
& +\gamma \log \left(D I S T_{i j}\right)+\sum_{r} \eta_{r} R G N_{i j}^{r}+u_{i j}
\end{aligned}
$$

For simplicity, some shorthand notations are defined and the equation is correspondingly rewritten as below:

$$
L V O T_{i j}=\alpha+\beta_{1} L G D P_{i j}+\beta_{2} L G P P C_{i j}+\gamma L D I S T_{i j}+\sum_{r} \eta_{r} R G N_{i j}^{r}+u_{i j}
$$

As noted before, the regional dummy will be defined on the base of the trading blocs identified by the cluster analysis. Then two experiments will be conducted. Firstly, the bloc's coefficient, i.e., $\eta_{r}$ will be tested for each year to see if the bloc phenomenon has been empirically supported. Secondly, by polling the annual data we will then investigate whether the bloc's coefficient is declining or rising over the period to reflect the likely changing pattern of bloc phenomenon for the two industries.

\footnotetext{
${ }^{7}$ Similarly, $\log \left(V O T_{i j}\right)$ will be rewritten as $L V O T_{i j}$ hereafter.

${ }^{8}$ This is also called Linder's Hypothesis. According to the related literature, the causes of intra-industry trade include economics of scale, heterogeneity of commodity, income similarity and multinational firms, and the degree of economic developments. See Feenstra et al (2001).
} 


\section{The Evolution of Trading Blocs in Textile Industry}

\section{A. Empirical Results from Cluster Analysis}

The results of the hierarchical cluster analysis of bilateral trade flows of the textile industry for 1970, 1980, 1990 and 2000 are described by Dendrograms (tree diagrams) in Figure 1A, 1B, 1C and 1D respectively and summarized in Table 1. Theoretically, the figure reveals the trading intensity within a given cluster. The higher the cluster fusion density the more intensive the intra-cluster trade flows. A somewhat arbitrary level of density threshold is taken while reading the outcome, as represented by the dotted line in each figure. Two important features of the textile trade are identified from the results:

\section{Two-bloc phenomenon in Textile Trade}

Two distinct trading blocs can be identified during the last three decades. As shown in the result for 1970 (Figure 1A; column 1970 in Table 1) we could easily pin down two trading blocs: The first one is mainly composed of countries in Europe i.e., Germany, Netherlands, Belgium-Lux., France, Italy, Switzerland and Austria, hereafter called bloc $\boldsymbol{E} \boldsymbol{U}$, in which the first five countries (Germany, Netherlands, Belgium-Lux., France, Italy) are relatively more integrated than the other two and hence denoted as the core of the group. The other one includes USA, Japan, Kong-Kong, Korea RP, UK, and Taiwan, Canada and Australia, mostly the countries around the Pacific Rim, to be called bloc PA hereafter. Clearly, the first five countries of USA, Japan, Kong-Kong, Korea RP, and UK form the core of this group. In addition and interestingly, the UK links to the PA group even before Taiwan. However, this is not the case in other year; that is, the UK links to the EU group in 1980, 1990 and 2000.

Besides the UK case in 1970, it seems that the trading blocs are to some extent reflecting a geographical distribution. That is, a country seems to trade more with closer countries. However, as will be illustrated later in the gravity model, there still exists a relatively higher intra-group trade even if the geographical factor (distance between countries) and the market size (GDP and GNP per capita) are taken into consideration.

The two-bloc pattern appears again in the results for 1980 (Figure 1B column 1980 in Table 1), 1990 (Figure 1C; column 1990 in Table 1) and 2000 (Figure 1D; column 2000 in Table 1), although some minor changes in the country composition 
Figure 1A. Dendrogram of the Hierarchic Cluster (1970_Textile Trade)

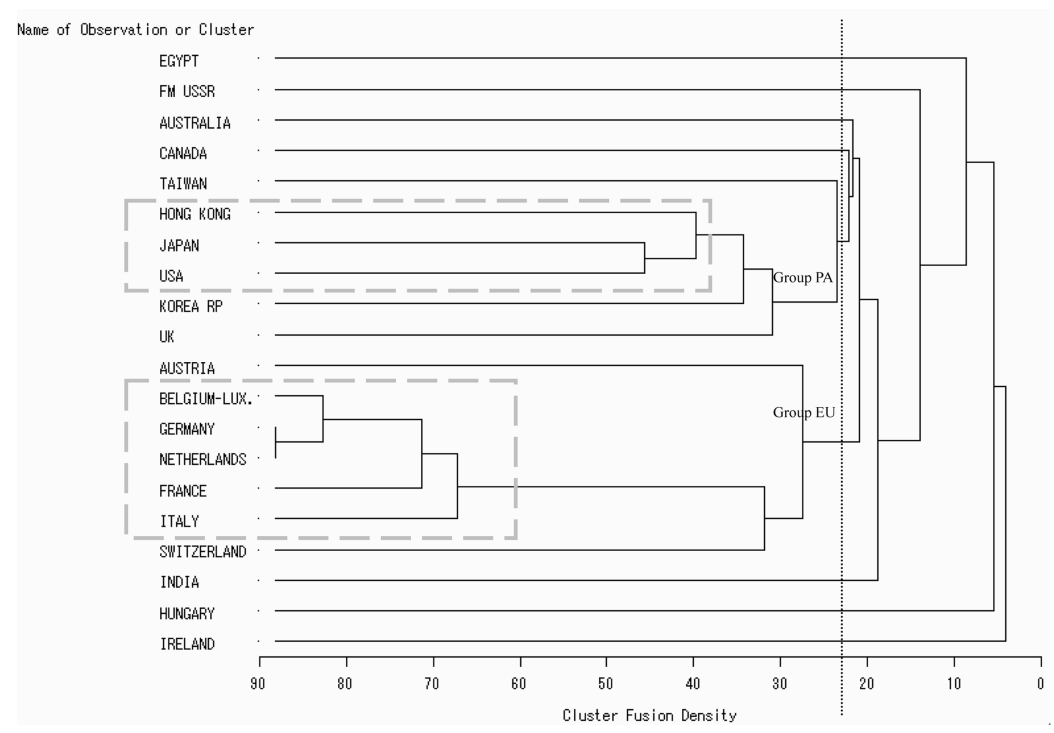

Figure 1B. Dendrogram of the Hierarchic Cluster (1980_Textile Trade)

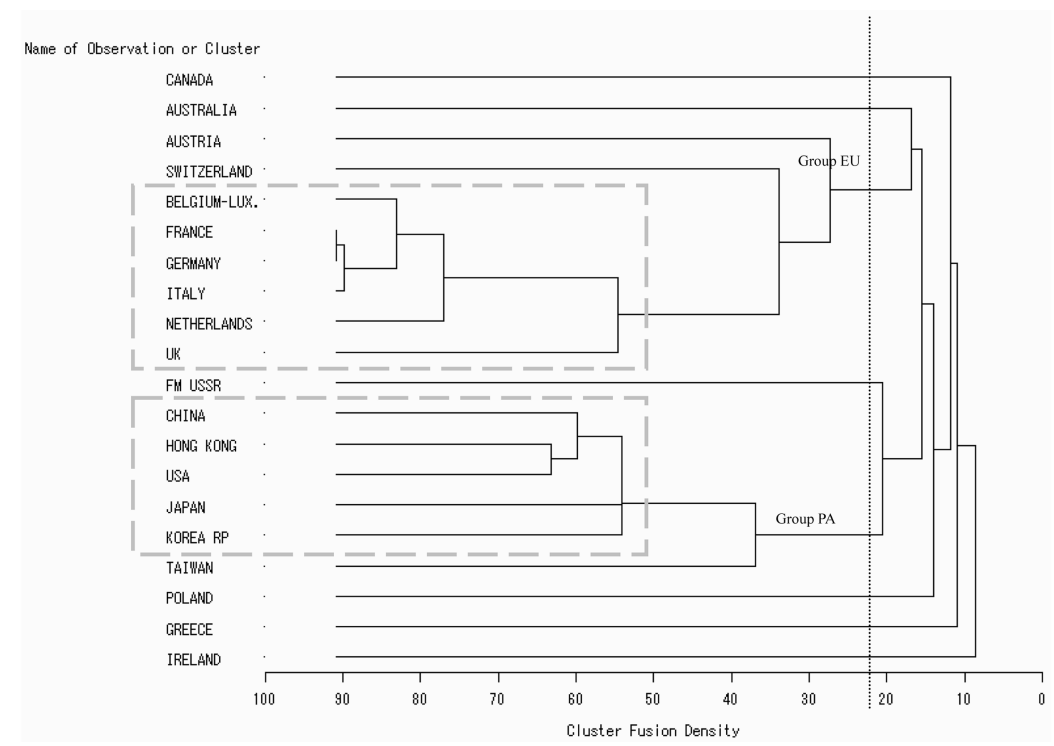

and the degree of trade intensity within each group can be observed in the figures.

\section{Declining EU Bloc and Rising PA Bloc}

As is shown in Figure 1A, the EU bloc in 1970 includes five core countries of 
Figure 1C. Dendrogram of the Hierarchic Cluster (1990_Textile Trade)

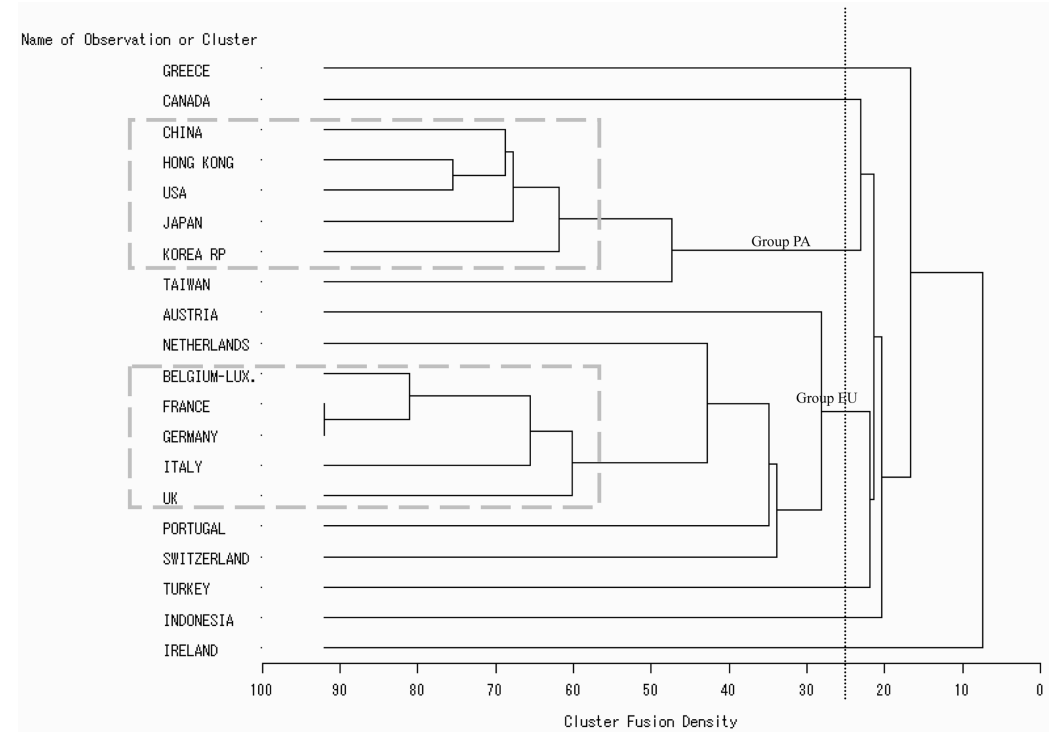

Figure 1D. Dendrogram of the Hierarchic Cluster (2000_Textile Trade)

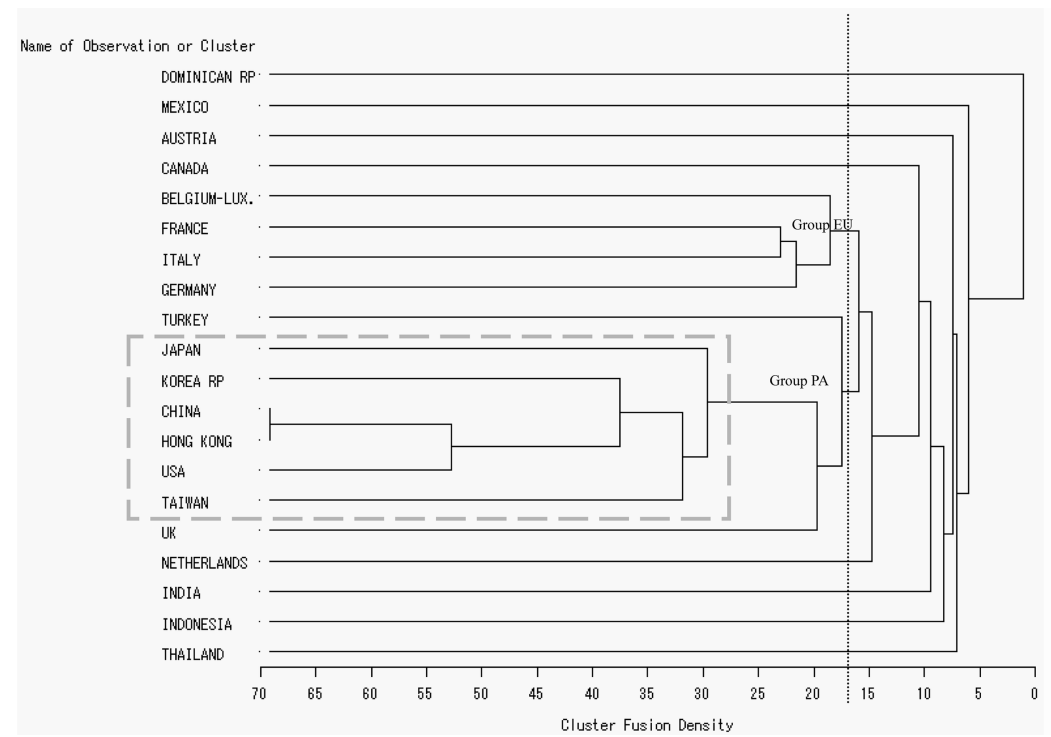

Germany, Netherlands, Belgium-Lux., France, Italy, and two peripheral countries of Switzerland and Austria. At the same time, the PA bloc includes the core countries of USA, Japan, Hong Kong, Korea RP, and UK, other peripheral 
Table 1. The VOT Share and Identified Blocs (Textile Industry)

Unit:\%

\begin{tabular}{|c|c|c|c|c|c|c|c|c|c|c|c|c|}
\hline \multirow{3}{*}{ Country } & \multicolumn{3}{|c|}{1970} & \multicolumn{3}{|c|}{1980} & \multicolumn{3}{|c|}{1990} & \multicolumn{3}{|c|}{2000} \\
\hline & \multirow{2}{*}{$\begin{array}{l}\text { VOT } \\
\text { Share }\end{array}$} & \multicolumn{2}{|c|}{ Bloc Bloc } & \multirow{2}{*}{$\begin{array}{l}\text { VOT } \\
\text { Share }\end{array}$} & \multicolumn{2}{|c|}{ Bloc Bloc } & \multirow{2}{*}{$\begin{array}{l}\text { VOT } \\
\text { Share }\end{array}$} & \multicolumn{2}{|c|}{ Bloc Bloc } & \multirow{2}{*}{$\begin{array}{l}\text { VOT } \\
\text { Share }\end{array}$} & \multicolumn{2}{|c|}{ Bloc Bloc } \\
\hline & & EU & PA & & EU & PA & & EU & PA & & EU & PA \\
\hline$\overline{\text { GERMANY }}$ & $10.58(1)$ & $\mathrm{C}$ & & $10.93(1)$ & $\mathrm{C}$ & & $10.63(1)$ & $\mathrm{C}$ & & $6.59(4)$ & $\mathrm{C}$ & \\
\hline USA & $8.61(2)$ & & $\mathrm{C}$ & $8.23(2)$ & & $\mathrm{C}$ & $8.97(2)$ & & $\mathrm{C}$ & $12.70(1)$ & & $\mathrm{C}$ \\
\hline JAPAN & $7.71(3)$ & & $\mathrm{C}$ & $5.31(6)$ & & $\mathrm{C}$ & $4.59(8)$ & $\mathrm{C}$ & $\mathrm{C}$ & $4.22(6)$ & & $\mathrm{C}$ \\
\hline ITALY & $5.96(4)$ & $\mathrm{C}$ & & $6.14(3)$ & $\mathrm{C}$ & & $6.70(4)$ & $\mathrm{C}$ & & $5.14(5)$ & $\mathrm{C}$ & \\
\hline FRANCE & $5.87(5)$ & $\mathrm{C}$ & & $6.13(4)$ & $\mathrm{C}$ & & $5.71(5)$ & $\mathrm{C}$ & & $4.19(7)$ & $\mathrm{C}$ & \\
\hline UK & $5.85(6)$ & & $P$ & $5.50(5)$ & $\mathrm{C}$ & & $4.67(7)$ & $\mathrm{C}$ & & $3.69(8)$ & & \\
\hline BELGIUM-LUX. & $4.90(7)$ & $\mathrm{C}$ & & $4.17(8)$ & $\mathrm{C}$ & & $3.45(10)$ & $\mathrm{C}$ & & $2.54(11)$ & $\mathrm{C}$ & \\
\hline NETHERLANDS & $4.89(8)$ & $\mathrm{C}$ & & $3.71(9)$ & $\mathrm{C}$ & & $2.85(11)$ & $\mathrm{P}$ & & $1.79(13)$ & & \\
\hline HONG KONG & $3.48(9)$ & & $\mathrm{C}$ & $4.94(7)$ & & $\mathrm{C}$ & $8.24(3)$ & & $\mathrm{C}$ & $7.49(3)$ & & $\mathrm{C}$ \\
\hline AUSTRALIA & $2.48(10)$ & & & $1.62(16)$ & $\mathrm{P}$ & & & & & & & \\
\hline SWITZERLAND & $2.29(11)$ & $\mathrm{P}$ & & $2.11(13)$ & $\mathrm{P}$ & & $1.83(13)$ & $\mathrm{P}$ & & & & \\
\hline FM USSR & $2.27(12)$ & & & $2.01(14)$ & & $\mathrm{P}$ & & & & & & \\
\hline CANADA & $1.86(13)$ & & $\mathrm{P}$ & $1.25(18)$ & & & $1.28(18)$ & & $\mathrm{P}$ & $1.62(16)$ & & \\
\hline SWEDEN & $1.71(14)$ & & & $1.32(17)$ & & & & & & & & \\
\hline AUSTRIA & $1.51(15)$ & $P$ & & $1.76(15)$ & $\mathrm{P}$ & & $1.64(14)$ & $\mathrm{P}$ & & & & \\
\hline INDIA & $1.50(16)$ & & & $1.01(19)$ & & & $1.20(20)$ & & & $1.51(17)$ & & \\
\hline KOREA RP & $1.22(17)$ & & $\mathrm{P}$ & $2.90(11)$ & & $\mathrm{C}$ & $3.68(9)$ & & $\mathrm{C}$ & $3.10(9)$ & & $\mathrm{C}$ \\
\hline TAIWAN & $1.22(18)$ & & $P$ & $2.38(12)$ & & $\mathrm{C}$ & $2.75(12)$ & & $\mathrm{P}$ & $2.14(12)$ & & $\mathrm{C}$ \\
\hline CHINA & 1.19 (19) & & & $3.26(10)$ & & $\mathrm{P}$ & $5.49(6)$ & & $\mathrm{C}$ & $10.11(2)$ & & $\mathrm{C}$ \\
\hline DENMARK & $1.17(20)$ & & & & & & & & & & & \\
\hline SPAIN & & & & & & & $1.32(16)$ & & & $1.74(15)$ & & \\
\hline MEXICO & & & & & & & & & & $2.85(10)$ & & \\
\hline POLAND & & & & $0.93(20)$ & & & & & & & & \\
\hline PORTUGAL & & & & & & & $1.51(15)$ & $\mathrm{P}$ & & $1.00(20)$ & & \\
\hline THAILAND & & & & & & & & & & 1.08 (19) & & \\
\hline TURKEY & & & & & & & $1.25(19)$ & & & $1.78(14)$ & & \\
\hline INDONESIA & & & & & & & $1.28(17)$ & & & $1.40(18)$ & & \\
\hline Sum of Top-20 & 75.17 & & & 64.74 & & & 68.50 & & & 64.05 & & \\
\hline
\end{tabular}

1. Numbers in parenthesis denote the rank of each country's VOT share in the world.

2. Bloc EU (Europe) and PA (Pacific Area) refer to the clusters identified by hierarchical cluster analysis. The component of each bloc is from Figure 1A, 1B, 1C and 1D respectively.

3. In each Bloc column, ' $\mathrm{C}$ ' denotes a core country, 'P' denotes periphery.

countries of Taiwan, Canada and/or Australia. In addition, a roughly comparison between the corresponding density level for the year of 1970, 1980, 1990 and 2000 , seems to indicate that the trading density within the EU bloc seems to 
decline over the period; on the contrary the trade intensity within the PA bloc increases. A rigorous method to confirm this observation is to use the gravity model to estimate empirically the trading bloc coefficient, and test whether the bloc coefficient has declined or not, which we now turn to.

\section{B. Empirical Evidence from the Gravity Equation (Textile Industry)}

According to the cluster analysis, the two-bloc phenomenon is composed of a EU group, and a PA group in each year's trade. The corresponding bloc dummies are designed as below:

BlocEU_70, representing the dummy variable of the Europe bloc for year 1970, takes value one if both trade partners belong to $E U$ bloc for 1970 identified by cluster analysis (see Figure 1A and Table 1), otherwise takes value zero. By the same way, BlocEU_ 80 is the dummy for EU bloc identified for 1980, and BlocEU_90 for 1990,BlocEU_00 for 2000.BlocPA_70 is the dummy of the Pacific area bloc identified for 1970,BlocPA_80 for 1980, BlocPA_90 for 1990, and BlocPA_OO for 2000.

Accordingly, the gravity equation to be estimated for each year is the following:

$$
\begin{aligned}
\operatorname{LVOT}_{i j}= & \alpha+\beta_{1} L G D P_{i j}+\beta_{2} L G N P P C_{i j}+\gamma_{3} L_{D I S T} \\
& +\eta_{1} \text { BlocEU }+\eta_{2} \text { BlocPA }+u_{i j}
\end{aligned}
$$

In addition to the bilateral trade data to compute the bilateral volume of trade for each observation, as noted earlier, for the cluster analysis we also need other macro variables to estimate the gravity model. The gravity variables of GDP, GNP per capita, are from the World Development Indicator (2002), World Bank. The transport distance is basically the sum of sea and inland routes. For sea route, the distance between major ports is computed. ${ }^{9}$ However, if more than one port is the case, then the average distance of all the navigation routes is adopted. The inland transport distance is measured between the ports and the capital, and an average distance is taken if necessary.

Table 2 reports the regression result of the corresponding gravity equations for each year of 1970, 1980, 1990 and 2000. In addition to the standard results of the gravity model for the gravity coefficients, that is, positive coefficient of GDP, GNP per capita and negative coefficient of the distance (LDIST), several important

${ }^{9}$ The distance of sea routes are computed according to the "Distance Between Ports" (1976) published by the Defense Mapping Agency, Hydrographic Center. 
findings regarding the trading blocs identified in the cluster analysis can be found from Table 2.

1. Two-Bloc phenomenon: Both EU bloc and PA bloc have significantly positive coefficient in the regression result for each year, indicating the within-group trade intensity is beyond normal. In other worlds, the two-bloc phenomenon identified by the cluster analysis is also empirically supported.

2. Declining EU bloc and increasing PA bloc: The coefficients for the bloc dummy declines over the sampling years, they are 4.39 for the year 1970 (coefficient of BlocEU_70), 4.199 for 1980 (BlocEU_80), 3.31 for 1990 (BlocEU_90) and 2.789 for 2000 (BlocEU_00). This indicates that the intra-

Table 2. Estimation of the Gravity Equation (Textile Industry)

Dependent Variable: Log of Bilateral VOT

\begin{tabular}{|c|c|c|c|c|c|c|c|c|}
\hline \multirow{2}{*}{$\begin{array}{c}\text { Year } \\
\text { Indep. Vars. }\end{array}$} & \multicolumn{2}{|c|}{1970} & \multicolumn{2}{|c|}{1980} & \multicolumn{2}{|c|}{1990} & \multicolumn{2}{|c|}{2000} \\
\hline & Coeff. & (t Value) & Coeff. & ( $t$ Value) & Coeff. & (t Value) & Coeff. & (t Value) \\
\hline Lgdp12 & 0.28716 & $(30.84)^{* *}$ & 0.17549 & $(14.09)^{* *}$ & 0.26878 & $(20.37)^{* *}$ & 0.36493 & $(38.01)^{* *}$ \\
\hline Lgnppc12 & 0.22566 & $(9.68)^{* *}$ & -0.04217 & $(-1.47)$ & 0.33605 & $(12.07)^{* *}$ & 0.2131 & $(10.84)^{* *}$ \\
\hline Ldist & -1.56594 & $(-47.71)^{* *}$ & -0.45314 & $(-13)^{* *}$ & -1.84854 & $(-34.46)^{* *}$ & -2.0825 & $(-56.72)^{* *}$ \\
\hline BlocEU_70 & 4.3854 & $(4.49)^{* *}$ & & & & & & \\
\hline BlocEU_80 & & & 4.1918 & $(27.85)^{* *}$ & & & & \\
\hline BlocEU_90 & & & & & 3.30786 & $(21.39)^{* *}$ & & \\
\hline BlocEU_00 & & & & & & & 2.78934 & $(\mathbf{1 7 . 5 2})^{* *}$ \\
\hline BlocPA_70 & 3.78531 & $(30.79)^{* *}$ & & & & & & \\
\hline BlocPA_80 & & & 6.00251 & $(7.61)^{* *}$ & & & & \\
\hline BlocPA_90 & & & & & 7.16817 & $(9.04)^{* *}$ & & \\
\hline BlocPA_00 & & & & & & & 6.22203 & $(7.15)^{* *}$ \\
\hline ADJ.R-sq & 0.6133 & & 0.6488 & & 0.5619 & & 0.5949 & \\
\hline F value & 1927.1 & & 1851.2 & & 1367.7 & & 2461.46 & \\
\hline Observations & 5459 & & 5018 & & 5336 & & 8387 & \\
\hline
\end{tabular}

Note: (1) Double asterisk denotes significant at the $5 \%$ level.

(2) BlocEU_70: Belgium-Lux, Germany, Netherlands, France, and Italy.

BlocEU_80: Belgium-Lux, Germany, Netherlands, France, UK.

BlocEU_90: Belgium-Lux, Germany, Netherlands, France, UK.

BlocEU_00: Belgium-Lux, Germany, France, and Italy.

(3) BlocPA 70 includes 5 economies, Hong Kong, Japan, USA, Korea, and UK in 1970.

BlocPA_80, BlocPA_90 and BlocPA_00 comprises the same group of countries, they are Hong Kong, Japan, USA, Korea, China and Taiwan. 
group textile trade intensity in the $E U$ bloc has been declining over the last three decades. This finding is also consistent with the trend of intra-group trade share for the EU bloc (which is define as the ratio of intra-group VOT to the world total VOT), $64.86 \%$ for $1970,61.72 \%$ for $1980,58.63 \%$ for 1990 and $28.9 \%$ for 2000 .

3. On the contrary, the intra-group trading intensity for the $P A$ bloc appears to be increasing during the same period, as indicted by the estimated coefficient of BlocPA (3.79 for 1970, 6.00 for $1980,7.17$ for 1990 , and then slightly decreases to 6.22 for 2000).

\section{The Evolution of Trading Bloc in Office Machine and Automatic Data Processing Industry}

\section{A. Trading Bloc identified by Cluster Analysis}

For the office machine and automatic data processing industry, the clustering results on bilateral trade intensity are described by the tree diagrams of Figure 2A, 2B, 2C and 2D for the years of 1970, 1980, 1990 and 2000 respectively. The summary is reported in Table 3 . The main features of this industry's trading pattern are as following:

\section{One-Bloc Phenomenon}

Unlike the two-bloc phenomenon found in the textile industry, there is only one trading bloc that can be identified for the automatic data processing industry; and more specifically, there appears to have only one-cluster which is composed of a major group of core countries surrounded by other peripheral countries.

\section{The core countries change from EU to East Asia.}

As shown in Table 3, in 1970 the first five intensively bilateral-trade bloc are USA, Germany, France, UK and Italy. If we extend the cluster further, then Netherlands links to the group before Japan. In 1980, the core-five includes USA, Germany, UK, France, and Italy, same as those in 1970 despite a minor ordering change. Again if the core-country extended further, Netherlands and then Japan are included. In brief, we may conclude from this finding that in the 1970s the only one major trading bloc is basically composed of US and countries in Europe. In 1990, one-bloc phenomenon still prevails; however, the first five core countries 
Figure 2A. Dendrogram of the Hierarchic Cluster (1970, Office Mach. \& Auto. Data Proc. Equip. Trade)

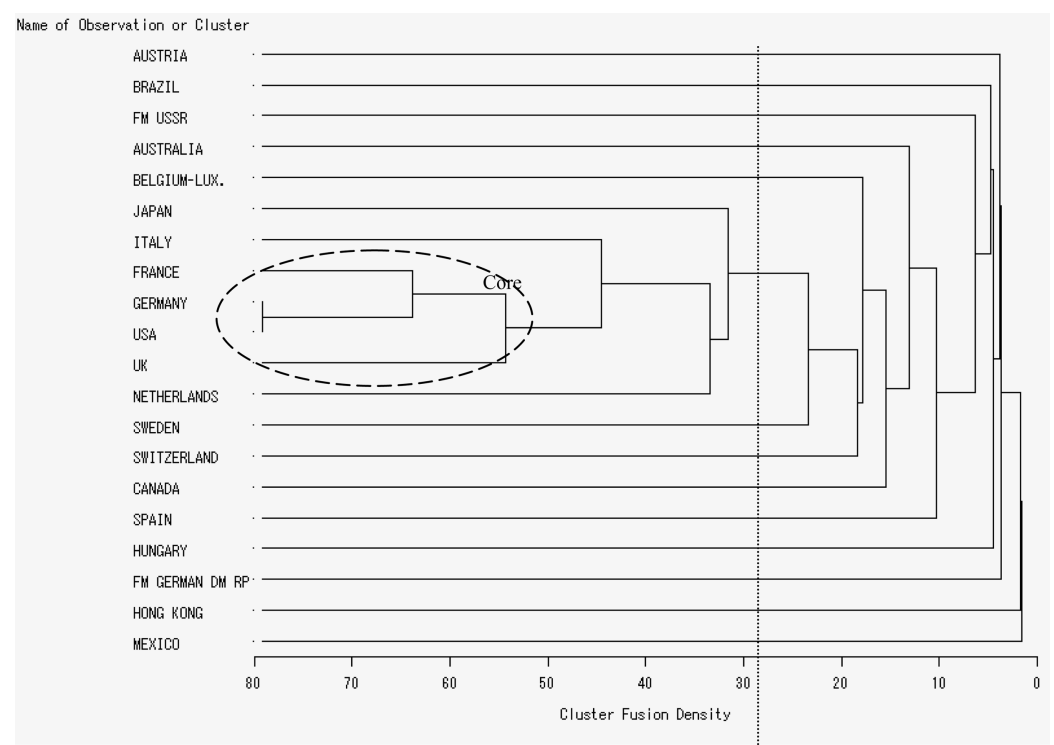

Figure 2B. Dendrogram of the Hierarchic Cluster (1980, Office Mach. \& Auto. Data Proc. Equip. Trade)

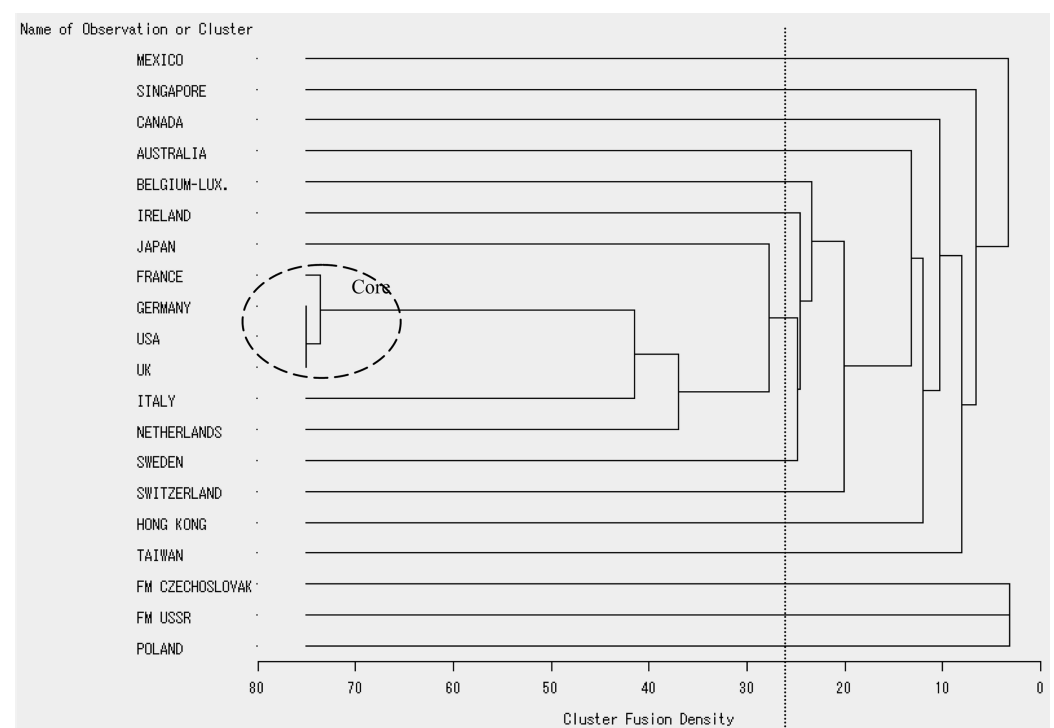

change to USA, UK, Germany, Japan and then France and/or Netherlands (France and Netherlands are linked to the cluster with equal intensity). Japan becomes the fourth core-country in the year, reflecting the rising role of Japan in the industry. 
Figure 2C. Dendrogram of the Hierarchic Cluster (1990, Office Mach. \& Auto. Data Proc. Equip. Trade)

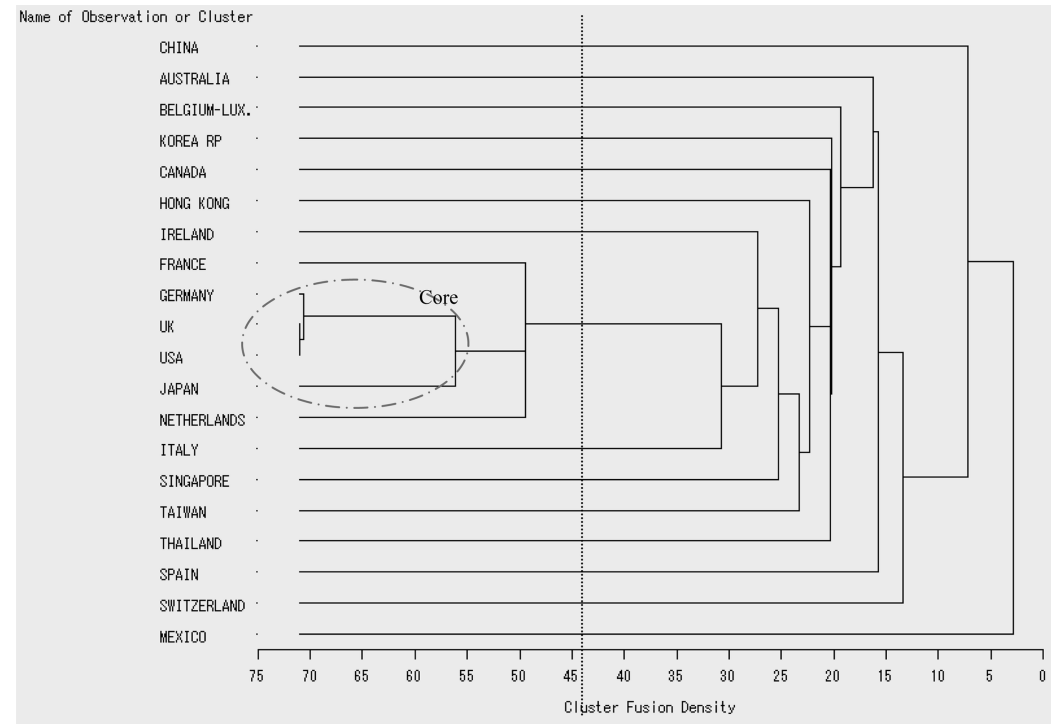

Figure 2D. Dendrogram of the Hierarchic Cluster (2000, Office Mach. \& Auto. Data Proc. Equip. Trade)

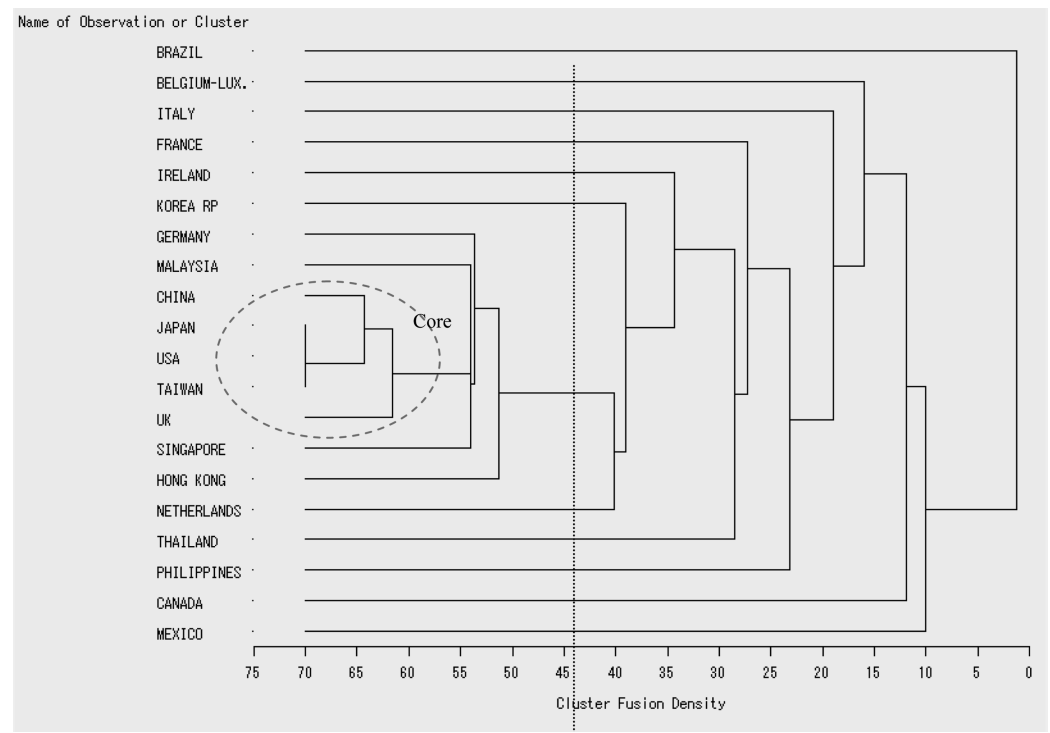

In fact, following the footstep of Japan, other East Asian countries, like Taiwan, Hong Kong, China, Malaysia, Singapore and South Korea, become the major trading countries in the automatic data processing industry. As is shown in the 
results from the cluster analysis for 2000 (Figure 2D, and the last column in Table 3 ), the five core countries comprise USA, Japan, and Taiwan, and China, then UK. Clearly, UK is the only country from Europe that is retained in core of five; on the

Table 3. VOT Share and Trading Blocs

(Office Mach. \& Automatic Data Proc. Equip.)

Unit:\%

\begin{tabular}{|c|c|c|c|c|c|c|c|c|}
\hline \multirow[b]{2}{*}{ Country } & \multicolumn{2}{|l|}{1970} & \multicolumn{2}{|l|}{1980} & \multicolumn{2}{|l|}{1990} & \multicolumn{2}{|l|}{2000} \\
\hline & VOT & Bloc & VOT & Bloc & VOT & Bloc & VOT & Bloc \\
\hline$\overline{\mathrm{USA}}$ & $23.968(1)$ & $\mathrm{C}$ & $22.588(1)$ & $\mathrm{C}$ & $22.083(1)$ & $\mathrm{C}$ & $18.774(1)$ & $\mathrm{C}$ \\
\hline GERMANY & $12.817(2)$ & $\mathrm{C}$ & $11.437(2)$ & $\mathrm{C}$ & $8.997(4)$ & $\mathrm{C}$ & $6.002(6)$ & $\mathrm{P}$ \\
\hline UK & $10.018(3)$ & $\mathrm{C}$ & $10.249(3)$ & $\mathrm{C}$ & $9.193(3)$ & $\mathrm{C}$ & $6.642(3)$ & $\mathrm{C}$ \\
\hline FRANCE & $8.799(4)$ & $\mathrm{C}$ & $8.062(4)$ & $\mathrm{C}$ & $5.385(5)$ & $\mathrm{P}$ & $3.440(13)$ & \\
\hline JAPAN & $7.048(5)$ & $\mathrm{P}$ & $6.594(5)$ & & $10.810(2)$ & $\mathrm{C}$ & $7.681(2)$ & $\mathrm{C}$ \\
\hline ITALY & $6.169(6)$ & $\mathrm{C}$ & $5.982(6)$ & $\mathrm{P}$ & $3.696(9)$ & & $1.453(17)$ & \\
\hline CANADA & $4.763(7)$ & & $4.205(7)$ & & $3.357(10)$ & & $2.483(14)$ & \\
\hline NETHERLANDS & $3.421(8)$ & $\mathrm{P}$ & $3.643(8)$ & $\mathrm{P}$ & $5.312(6)$ & $\mathrm{P}$ & $6.124(5)$ & \\
\hline SWEDEN & $3.213(9)$ & $\mathrm{P}$ & $2.638(9)$ & & $1.398(16)$ & & & \\
\hline SWITZERLAND & $1.764(10)$ & $\mathrm{P}$ & $1.528(13)$ & & $1.233(17)$ & & & \\
\hline BELGIUM-LUX. & $1.754(11)$ & $\mathrm{P}$ & $1.828(11)$ & & $1.423(15)$ & & $1.221(19)$ & \\
\hline AUSTRALIA & $1.382(12)$ & & $1.251(15)$ & & $1.166(18)$ & & & \\
\hline HUNGARY & $1.329(13)$ & & & & & & & \\
\hline SPAIN & $1.155(14)$ & & $1.418(14)$ & & $1.572(14)$ & & $0.868(20)$ & \\
\hline BRAZIL & $1.077(15)$ & & $0.954(17)$ & & & & & \\
\hline DENMARK & $0.914(16)$ & & $0.770(19)$ & & & & & \\
\hline FM USSR & $0.772(17)$ & & $0.999(16)$ & & & & & \\
\hline SOUTH AFRICA & $0.763(18)$ & & $0.719(20)$ & & & & & \\
\hline ARGENTINA & $0.668(19)$ & & & & & & & \\
\hline HONG KONG & $0.651(20)$ & & $1.848(10)$ & & $2.037(12)$ & & $3.988(9)$ & $\mathrm{P}$ \\
\hline IRELAND & & & $1.650(12)$ & & $2.551(11)$ & & $3.632(10)$ & \\
\hline KOREA RP & & & & & $1.724(13)$ & & $3.573(11)$ & \\
\hline MALAYSIA & & & & & & & $3.486(12)$ & $\mathrm{P}$ \\
\hline MEXICO & & & & & & & $2.428(15)$ & \\
\hline PHILIPPINES & & & & & & & $1.288(18)$ & \\
\hline CHINA & & & & & & & $4.213(8)$ & $\mathrm{C}$ \\
\hline SINGAPORE & & & & & $5.232(7)$ & & $6.198(4)$ & $\mathrm{P}$ \\
\hline AUSTRIA & & & $0.814(18)$ & & $0.796(20)$ & & & \\
\hline TAIWAN & & & & & $3.723(8)$ & & $5.762(7)$ & $\mathrm{C}$ \\
\hline THAILAND & & & & & 0.992 (19) & & $1.657(16)$ & \\
\hline Sum of Top-20 & 92.444 & & 89.175 & & 92.679 & & 90.913 & \\
\hline
\end{tabular}

1. Numbers in parenthesis denote the rank of each country's VOT share in the world.

2. The component of each bloc is from Figure $2 \mathrm{~A}, 2 \mathrm{~B}, 2 \mathrm{C}$ and $2 \mathrm{D}$ respectively.

3. In each Bloc column, ' $\mathrm{C}$ ' denotes a core country, 'P' denotes periphery. 
contrary, in addition to Japan two more Asian economies of Taiwan and China move into the core. If we extend the cluster members to include more countries, two countries from Southeast Asia, Singapore and Malaysia, are linked to the core group before Germany. Further extension of the cluster brings Hong Kong, then Netherlands and South Korea into the spotlight, two from Asian and one from Europe.

In sum, according to the bilateral trade intensities, only one trading bloc in the industry could be identified by the cluster analysis. However, the core countries vary over the last three decades. In the 1970 and 1980, the core countries were mainly composed of the USA and countries from Europe. Then, the core countries gradually changed to countries from East Asia, leading by Japan and then followed by other Asian countries such as Taiwan, China, Singapore, Malaysia, Hong Kong and South Korea.

\section{B. Empirical Evidence from the Gravity Equation for Automatic Data Process- ing Industry}

Since only one bloc is identified by the cluster analysis for each year, thus each regression contains only one bloc dummy, that is Bloc 70 for the 1970 , Bloc 80 for 1980, Bloc 90 for 1990 and Bloc00 for 2000. More specifically, the gravity equation to be estimated for the automatic data processing industry for each year is as below:

$$
L V O T_{i j}=\alpha+\beta_{1} L G D P_{i j}+\beta_{2} L G N P P C_{i j}+\gamma_{3} L D I S T_{i j}+\eta_{1} \text { Bloc_year }+u_{i j}
$$

The estimated results are reported in Table 4. In addition to the normal results for those standard gravity variables, GDP, GNP per capita and the distance, we can easily find that all the identified blocs, one in every year, have significantly positive coefficient. That is, the bloc found by the cluster analysis is also empirically supported by the gravity equation.

Another interesting experiment is to check the intra-group trade intensity for the bloc of 1970, i.e., the bloc dummy of Bloc70. As noted before, we would expect the declining intensity for the earlier group. On the contrary, we would expect the identified bloc for 2000 , i.e., Bloc00 to have a rising pattern of intra-bloc trade intensity over the decades. The corresponding results are reported in Table 5. On the left hand side of the table, the bloc dummy included in each year's gravity equation is the Bloc70. On the right hand side of Table 5, the bloc dummy is 
Table 4. Gravity Equation (SITC75: 1970, 1980, 1990 and 2000)

Dep. Variable: Log of Bilateral VOT

\begin{tabular}{lcccc}
\hline \multicolumn{1}{c}{ Year } & 1970 & 1980 & 1990 & 2000 \\
\cline { 2 - 5 } Indep. Vars. & Coeff. (t value) & Coeff. $(\mathrm{t} \text { value) })^{* *}$ & Coeff. $(\mathrm{t}$ value) & Coeff. (t value) \\
\hline Lgdp12 & $0.103(15.07)^{* *}$ & $0.132(11.82)^{* *}$ & $0.118(11.12)^{* *}$ & $0.204(24.75)^{* *}$ \\
Lgnppc12 & $0.312(18.37)^{* *}$ & $0.438(17.72)^{* *}$ & $0.654(29.55)^{* *}$ & $0.480(28.43)^{* *}$ \\
Ldist & $-0.874(-36.25)^{* *}$ & $-1.305(-30.71)^{* *}$ & $-1.586(-36.70)^{* *}$ & $-1.721(-55.87)^{* *}$ \\
Bloc70 & $7.179(\mathbf{1 0 . 5 0})^{* *}$ & & & \\
Bloc80 & & $7.019(\mathbf{9 . 9 2})^{* *}$ & & \\
Bloc90 & & & $6.642(\mathbf{9 . 6 4})^{* *}$ & \\
Bloc00 & & & & $8.381(\mathbf{1 7 . 4 5})^{* *}$ \\
ADJ.R-sq & 0.40 & 0.49 & 0.58 & 0.59 \\
F value & 850.32 & 1091.88 & 1807.06 & 2866.29 \\
Observations & 4942 & 4679 & 5285 & 8258 \\
\hline
\end{tabular}

Note: (1) Double asterisk denotes significant at the $5 \%$ level.

(2) Bloc70: Germany, France, Italy, Netherlands, UK and USA.(6 countries)

(3) Bloc80: Same as Bloc70

(4) Bloc90: Germany, France, Japan, Netherlands, UK and USA.(6 countries)

(5) Bloc00: Germany, China, Hong Kong, USA, Japan, Taiwan, Malaysia, Singapore and UK ( 9 countries)

replaced by Bloc00. We could easily find the coefficient for the Bloc 70 significantly declines from the 7.179 for 1970 , to 7.02 for $1980,6.01$ for 1990 and 5.78 for 2000 . On the contrary, the estimated coefficient for the bloc dummy of 2000, Bloc00 increases over the periods, that is, 3.29 for 1970, 6.05 for 1980, 7.20 for 1990 and 8.38 for 2000 .

\section{Concluding Remarks}

Along with the trend of globalization, production process becomes more and more disintegrated across country borders. This in turn will affect the trade pattern, not only the rising volume of trade but also the trading bloc across countries. This paper argues that the trade network induced by the production disintegration is not boundless; instead it depends on the availability of technology and/or the distribution of foreign direct investment. Thus, different industries with different technological features would be expected to have different pattern of countries involved.

By clustering analysis on the bilateral trade intensity, and complemented with the gravity equation estimation, this paper investigates the evolution of trading pattern in the conventional textile industry, and a modern high-tech industry of 
Table 5. Gravity Equation (SITC75: 1970, 1980, 1990 and 2000) Dep. Variable: Log of Bilateral VOT

\begin{tabular}{|c|c|c|c|c|c|c|c|c|c|c|}
\hline Year & 1970 & 1980 & & 1990 & 02000 & & 1970 & 1980 & 1990 & 2000 \\
\hline $\begin{array}{l}\text { Indep. } \\
\text { Vars. }\end{array}$ & Coeff. (t value) & Coeff. & (t value) & Coeff. (t value) & Coeff. & (t value) & Coeff. (t value) & Coeff. ( $\mathrm{t}$ value) & Coeff. (t value) & Coeff. ( $\mathrm{t}$ value) \\
\hline Lgdp12 & $0.103(15.07)^{* *}$ & 0.132 & $(11.82)^{* *}$ & $0.118(11.07)^{* * *}$ & 0.207 & $(24.74)^{* *}$ & $0.100(14.60)^{* *}$ & $0.130(11.73)^{* *}$ & $0.115(10.96)^{* * *}$ & $0.204(24.75)^{* * *}$ \\
\hline Lgnppc12 & $0.312(18.37)^{* *}$ & 0.438 & $(17.72)^{* *}$ & $0.657(29.60)^{* *}$ & 0.487 & $(28.45)^{* *}$ & $0.320(18.79)^{* * *}$ & $0.448(18.28)^{* * *}$ & $0.655(29.98)^{* *}$ & $0.480(28.43)^{* *}$ \\
\hline Ldist & $-0.874(-36.2)^{* *}$ & -1.305 & $(-30.7)^{* *}$ & $-1.589(-36.6)^{* * *}$ & -1.747 & $(-55.8)^{* *}$ & $-0.873(-36.0)^{* *}$ & $-1.313(-31.3)^{* *}$ & $-1.573(-36.9)^{* *}$ & $-1.721(-55.8)^{* *}$ \\
\hline Bloc70 & $7.179 \mathbf{( 1 0 . 5 0 )}^{* *}$ & 7.019 & $(9.92)^{* *}$ & $6.010(7.92)^{* *}$ & 5.783 & $(7.66)^{* *}$ & & & & \\
\hline Bloc00 & & & & & & & $3.285(8.93)^{* *}$ & $6.054(13.43)^{* * *}$ & $7.205(15.0)^{* *}$ & $8.381(17.4)^{* * *}$ \\
\hline ADJ.R-sq & 0.5035 & 0.49 & & 0.58 & 0.57 & & 0.41 & 0.49 & 0.59 & 0.59 \\
\hline F value & 1251.27 & 1091.8 & & 1789.5 & 2724.7 & & 837.73 & 1130.7 & 1883.9 & 2866.2 \\
\hline $\begin{array}{l}\text { Observa- } \\
\text { tions }\end{array}$ & 4942 & 4679 & & 5285 & 8258 & & 4942 & 4679 & 5285 & 8258 \\
\hline
\end{tabular}

Note: (1) Double asterisk denotes significant at the $5 \%$ level.

(2) Bloc70: Germany, France, Italy, Netherlands, UK and USA.(6 countries)

(3) Bloc00: Germany, China, Hong Kong, USA, Japan, Taiwan, Malaysia, Singapore and UK (9 countries) 
automatic data processing equipment. The major findings are as follows:

For the textile industry, two-bloc phenomenon exists, that is, two distinct trading blocs could be identified during the last three decades: The first one called EU Bloc, is mainly composed of countries in Europe, and the other one, called PA Bloc, includes USA, Japan, and others mostly around the Pacific Rim. In addition to this two-bloc phenomenon, we also find that the EU bloc is declining in terms of in-group trading intensity; on the contrary, the PA bloc is getting more integrated in terms of the intra-group trade intensity.

For the automatic data processing industry, only one trading bloc could be identified by the cluster analysis and empirically supported by the gravity model. However, the core countries vary over the last three decades. In the 1970 and 1980, the core countries were mainly composed of the USA and countries from Europe. Then, the core countries gradually changed to countries from East Asia, leading by Japan and then followed by other Asian countries such as Taiwan, China, Singapore, Malaysia, Hong Kong and South Korea.

\section{Acknowledgments}

The authors are grateful for helpful comments and suggestions from and anonymous referee and editors and financial support from National Science Council, Taiwan (NSC 93-2415-J002-026). The usual caveats apply.

Received 8 November 2005, Accepted 13 June 2006

\section{Reference}

Anderson, J. E. (1979), A Theoretical Foundation for the Gravity Equation, American Economic Review, 69, 106-116.

Artis, M. J. and W. Zhang (2001), Core and Periphery in EMU: A Cluster analysis, Economic Issues, 6(2), 39-59

Bergstrand, J. H. (1985), The Gravity Equation in International Trade: Some Microeconomic Foundations and Empirical Evidence, Review of Economics and Statistics, 67, 474-481.

Bonturi, M. and K. Fukasaku (1993), Globalization and Intra-Firm Trade: An Empirical Note, OECD Economic Studies, 145-159.

Deardorff, A. V. (1984), Testing Trade Theories and Predicting Trade Flows, Handbook of International Economics, Vol. I, Amsterdam: 1984, 456-517.

Duran, B. S. and P. L. Odell (1974), Cluster Analysis; A Survey, Springer-Verlag: New 
York.

Eichengreen, B. and D. A. Irwin (1995), Trade Blocs, Currency Blocs and the Reorientation of Trade in the 1930s, Journal of International Economics, 38, 1-24.

Eichengreen, B. and D. A. Irwin (1996), The Role of History in Bilateral Trade Flows, NBER Working Paper No. 5565.

Feenstra, R. C. (1998), Integration of Trade and Disintegration of Production in the Global Economy, Journal of Economic Perspectives, 12(4), 31-50.

Feenstra, R. C., Markusen, J. A. and A K. Rose (2001), Using the Gravity Equation to Differentiate Among Alternative Theories of Trade, Canadian Journal of Economics, 34(2): 430-447.

Frankel, J. (1992), Is Japan Creating a Yen Bloc in East Asia and the Pacific? Paper prepared for the NBER conference on Japan and the U.S. in Pacific Area.

Frankel, J. A. and S. J. Wei (1995), The New Regionalism and Asia: Impact and Options, Working paper PB 95-10.

Grant, R. J., M. C. Papadakis, and J. D. Richardson (1993), Global Trade Flows: Old Structures, New Issues, Empirical Evidence, Pacific Dynamism and the International Economic system, ch.1, 17-63.

Krugman, P., (1995), Growing World Trade: Causes and Consequences, Brookings Papers on Economic Activity, 1, 327-377.

Linnemann, H. (1966), An Econometric Analysis of International Trade Flows, NorthHolland: Amsterdam.

Nunnenkamp, P., Gundlach, E. and J. P. Agarwal (1994), Globalization of Production and Markets, Institut fur Weltwirtschaft an der Universitat Kiel Kieler Studien, vol. 262. Tubingen: Mohr (Siebeck), xii, 187.

Rauch, J. E. (1999), Networks versus Markets in International Trade, Journal of International Economics, 48, 7-35.

Tinbergen, J. (1962), Shaping the World Economy: Suggestions for an International Economic Policy, New York.

Vernables, A. J. (1996), Equilibrium Location of Vertically Linked Industries, International Economic Review, 37(2), 341-359. 